\title{
Safety, efficacy and patient acceptability of the combined estrogen and progestin transdermal contraceptive patch: a review
}

\author{
Alessandra Graziottin \\ Center of Gynecology and Medical \\ Sexology, H San Raffaele Resnati, Via \\ Santa Croce 10/a, 20I23 Milano, Italy
}

\begin{abstract}
The worldwide introduction of the first, unique patch for hormonal contraception (ethinyl estradiol/norelgestromin, EE/NGMN patch) was widely recognized as a significant event in the development of drug delivery systems. This innovation offers a number of advantages over the oral route, and extensive clinical trials have proved its safety, efficacy, effectiveness, and tolerability. The weekly administration and ease of use/simplicity of the EE/NGMN patch contribute to its acceptability, and help to resolve the two main problems of non-adherence, namely early discontinuation and inconsistent use. The patch offers additional benefits to adolescents (improvement of dysmenorrhea and acne), adults (improvement in emotional and physical well-being, premenstrual syndrome, and menstrual irregularities), and perimenopausal women (correction of hormonal imbalance, modulation of premenopausal symptoms), thus providing high satisfaction rates (in nearly $90 \%$ of users). Since its introduction, the transdermal contraceptive patch has proved to be a useful choice for women who seek a convenient formulation which is easy to use, with additional, non-contraceptive tailored benefits for all the ages.
\end{abstract}

Keywords: transdermal, hormonal contraceptive, patient satisfaction, patient adherence

\section{Introduction: transdermal drug delivery}

Patient adherence is a key issue that must be addressed to ensure the efficacy of hormonal contraception. Combined hormonal contraceptives are effective forms of reversible contraception, whose benefits have been established by a wealth of studies (D'Souza and Guillebaud 2002; Petitti 2003). Provided that they are taken regularly and correctly on a once-daily regimen, combined hormonal contraceptives are more than $99 \%$ effective and almost $100 \%$ reliable, the first-year pregnancy rate being less than $0.5 \%$ among perfectly conscientious users (Potter et al 1996). However, from $19 \%$ to $47 \%$ of oral contraceptive users miss one or more pills per cycle (Pierson et al 2003) and this gap translates into thousands of unintended pregnancies annually (Archer et al 2002). A more convenient method of administration has thus been sought, to reduce the risk of "missing pills".

Transdermal systems represent a milestone innovation in drug delivery, offering a number of advantages over the oral route (Prausnitz et al 2004), They include multiday and more convenient dosing, especially for the sustained release of short half-life drugs (Burkman 2007). The main drawback of this technology is that only a limited number of drugs can be delivered by passive diffusion from a patch, because low molecular weight, high lipophilic property, and a small required dose are essential for a molecule to permeate the skin (Burkman 2007). Thus the introduction of the first, unique patch for transdermal hormonal contraception (ethinyl estradiol/norelgestromin, EE/NGMN patch) was widely acknowledged as a significant step in the development of transdermal drug delivery (Prausnitz et al 2004). 
The central aim of this article is to review the main evidence supporting the use of the transdermal contraceptive EE/NGMN patch, with particular reference to patient adherence and satisfaction.

\section{Methods}

A Medline search was made during April 2008, to identify all types of articles in English on the EE/NGMN patch, including prospective open label and controlled clinical studies. The keywords were: "transdermal", "contraceptive", "ethinyl estradiol", "norelgestromin", "compliance", "adherence", "persistence", "acceptability", "therapeutic alliance", and "patient satisfaction". Congress communications on the same topics were also searched, to include more recent clinical studies. When no refererences are cited, the reader can assume that the author's clinical observations are presented.

\section{Main characteristics and clinical development}

The EE/NGMN patch is an innovative, three-layer hormonal contraceptive system that provides similar efficacy to oral contraceptives, with the substantial benefit of once-weekly administration. The patch is applied once weekly for 3 consecutive weeks, followed by a patch-free week. As a result, users need only actively comply with dosing once weekly on the same day (Pierson et al 2003).

The transdermal contraceptive EE/NGMN patch has the same mechanisms of action as combined oral contraceptives. After the patch is applied, hormones appear rapidly in the circulation, reaching a plateau after approximately 48 hours, which is maintained at this level during the 7-day wear period. On average, each EE/NGMN patch delivers $150 \mu \mathrm{g}$ of norelgestromin (the primary active metabolite of norgestimate) and $20 \mu \mathrm{g}$ of ethinyl estradiol daily to the systemic circulation (O'Connel and Burkman 2007).

The pharmacokinetic properties (Abrams et al 2001; Burkman 2007) of the EE/NGMN transdermal patch provide particular benefits over combined oral contraceptives (Table 1).

\section{Efficacy}

Three pivotal phase III clinical studies have consistently confirmed the contraceptive efficacy of the transdermal EE/ NGMN patch, either in comparison with oral contraceptives (Hedon et al 2000; Audet et al 2001) or according to an open, non-comparative trial design (Smallwood et al 2001).

Pooled analyses of pivotal trials on more than 3,300 women and more than 22,000 treatment cycles showed favorable results: the EE/NGMN patch had an overall annual probability of pregnancy (method failure plus user failure) of $0.8 \%$ and a method failure probability of $0.6 \%$. Efficacy and cycle control were similar to those of established oral contraceptives, and were comparable across age and racial groups (Zieman et al 2002). Follicular size and incidence of ovulation proved to be significantly reduced among patch users compared with those in women using oral contraceptives, both in normal cycles and after planned dosing errors (Pierson et al 2003).

Besides controlled studies, effectiveness was tested in real life conditions. Results of a large European, open-label study evaluating women's experience with the transdermal contraceptive patch during routine use were recently disclosed at a congress (Jakimiuk et al 2006a; Jakimiuk et al 2006b). In the study, 573 healthy women were followed up for six, 4-week treatment cycles. The transdermal contraceptive patch was shown to be a reliable method of contraception, with a Pearl Index (the number of pregnancies per 100 women-years

Table I Clinical advantages of a transdermal system for contraception

Allows longer, multiday, more convenient dosing intervals than the once daily administration of oral contraceptives (Burkman 2007)

Improves patient compliance (Abrams et al 200I)

Can reduce side effects by avoiding peak high concentrations and ensuring continuous, sustained hormonal release (Abrams et al 200 I)

Avoids first-pass liver metabolism, thus enabling the use of lower doses to achieve efficacy and reducing the chances of drug interactions (Abrams et al 200I)

Unaffected by bouts of vomiting and/or diarrhea, which prevent adequate absorption by the gut (Abrams et al 200I)

Can easily be withdrawn if necessary (Burkman 2007)

More forgiving of dosing errors: back up contraception not needed if patch change is forgotten for I-2 days in the middle of a 4-week cycle (weeks 2 and 3 ) (Abrams et al 200I)

Eases compliance of use in cases of jet-lag and frequent flying

Allows safe administration in women with lactose and gluten intolerance 
of use) of 0.43 (95\% CI: -0.41 to 1.27 ) and a Pearl Index for patients who reported perfect compliance of $0.48(95 \%$ CI: -0.47 to 1.43 ). Thus both indexes were comparable to those of other popular forms of hormonal contraception.

A further study (Sonnenberg et al 2005) estimated the contraceptive effectiveness of the patch versus oral contraceptives in real life conditions. The probability of pregnancy with the transdermal patch was shown to be lower than with oral contraceptives in all age groups, included younger women (Figure 1). Therefore, the effectiveness of the patch is expected to exceed that of oral contraceptives, due to an increased rate of perfect use.

Adhesion could be a potential concern, because optimal drug delivery can be achieved only if the patch remains adhered to the user's skin. In fact the adhesive reliability of the contraceptive patch has proved to be excellent and consistent: the two clinical trials showed that only $1.8 \%$ and $2.9 \%$ of patches required replacement because of complete or partial detachment, respectively. Furthermore, it was observed that patch adhesion tended to improve over treatment cycles, probably because participants learned the proper application technique with continued use. Finally, specific studies showed that the contraceptive patch detachment rate was unaffected by heat, humidity, and exercise (Zacur et al 2002).

In conclusion, the EE/NGMN patch provides, on a onceweekly schedule, at least the same efficacy as marketed oral contraceptives administered on a daily regimen, with the added benefits of sustained hormone concentrations and greater "forgiveness" of dosing errors. Even if a scheduled patch change is missed for 2 days during weeks 2 and 3 of a 4-week cycle, clinical efficacy is maintained, and backup contraception is not needed (Burkman 2007). Adhesion properties are reassuring for women who enjoy participating in exercise, as they can maintain all their usual activities including bathing, swimming, jogging, and using a whirlpool or a sauna (Abrams et al 2001; Zacur et al 2002).

\section{Tolerability and safety}

The pooled analysis of safety and tolerability data across three pivotal studies showed that the adverse effect profile of the EE/NGMN patch was fairly similar to that of oral contraceptives, the most frequent adverse events being headache and nausea (Figure 2). A few notable differences were reported in patch users: transient, mild to moderate application site reactions, as expected, and breast discomfort symptoms, which generally resolved after 3 months of use. Local tolerability was shown to be good, with low potential for irritation and no potential for photo-toxicity (Sibai et al 2002). However, women with atopia and allergic skin diseases are more vulnerable to allergic reactions or local skin irritation.

Further studies addressed some safety issues and showed that oral and transdermal contraception with similar hormones induced similar effects on vascular risk markers (Johnson et al 2008; Kluft et al 2008). A review of post-marketing safety and surveillance data for progestin oral contraceptives containing norgestimate and ethinyl estradiol provided useful information about the relative rate of vascular events (Lippman and Shangold 1997). These data fully supported the favorable

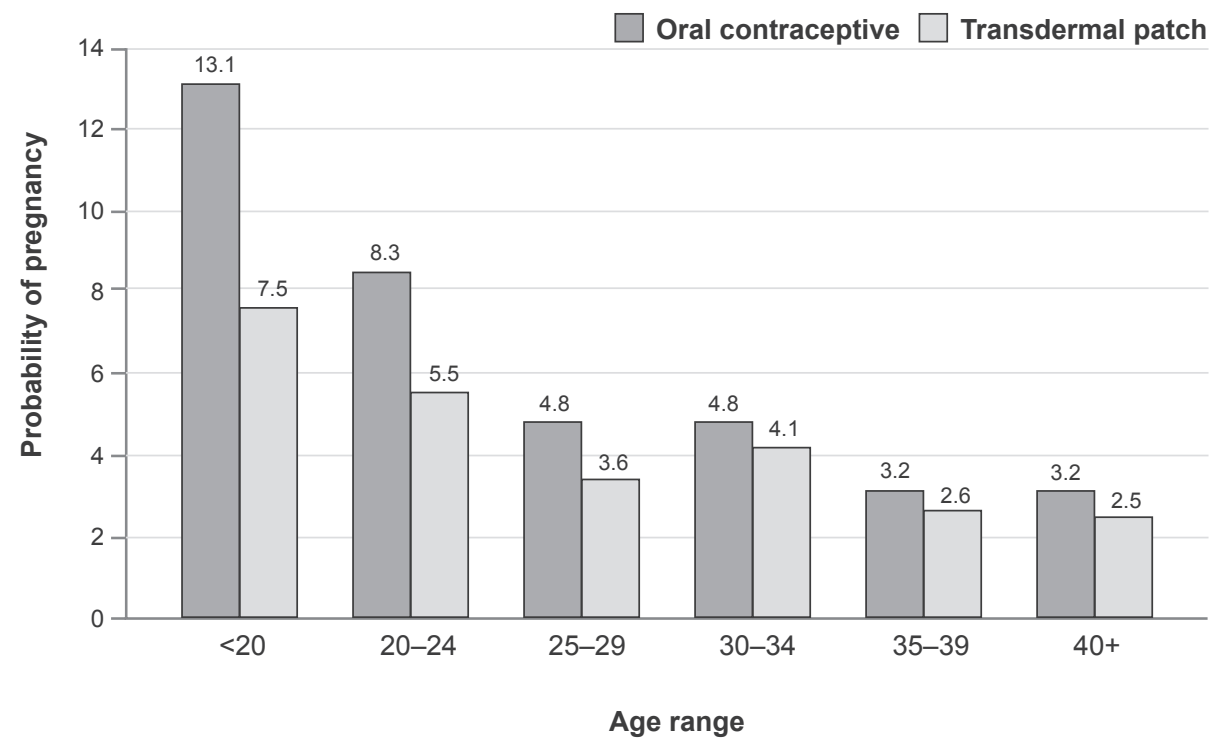

Figure I Age-specific pregnancy rates for oral contraceptives and patch calculated in real life conditions (From data of Sonnenberg et al 2005). 
cardiovascular safety profile of norgestimate-containing oral contraceptives. A recently published, nested, casecontrol, epidemiologic study, which compared different routes of administration, and included a further 17 months of follow up, showed that the risk of non-fatal venous thromboembolism was similar in the contraceptive patch and norgestimate-containing oral contraceptives with $35 \mu \mathrm{g}$ of ethinyl estradiol (Jick et al 2006; Jick et al 2007). Furthermore, the EE/NGMN patch showed no evidence of an increased risk of cerebral venous sinus thrombosis compared with levonorgestrel-containing, norgestimate-containing, and desogestrel-containing oral contraceptives (Jick and Jick 2006). Moreover, ischemic stroke and acute myocardial infarction were rarely reported among contraceptive patch users (Jick and Jick 2007). Only one epidemiologic study reported a more than two-fold increase in the risk of venous thromboembolism, but not arterial thromboembolic events, for the transdermal contraceptive system, compared with the same risk in users of norgestimate-containing oral contraceptives (Cole et al 2007). These data were not confirmed by other studies; moreover, the estimated incidence of venous thrombo-embolism per 100,000 women-years was 40.8 for contraceptive patch users, which is similar to that reported in studies of third generation progestins (Burkman 2007).

Therefore the EE/NGMN contraceptive patch experience confirms previously reported findings on safety in hormonal oral contraceptives: provided that they are not prescribed to women at risk, and that they contain a low dose of ethinyl estradiol and suitable progestins (eg, norgestimate), their net health benefit is great, even when the health risks are taken into account (Petitti 2003).

\section{Perfect dosing}

Patch users were better able to follow the dosing regimen than users of daily oral contraceptive (Creasy et al 2001). Indeed transdermal contraception has been shown to improve the percentage of cycles with perfect dosing compared with oral contraceptives. Pooled data across the three pivotal studies showed that the percentage of cycles with perfect dosing was significantly higher with the patch than with oral contraceptives (Archer et al 2004).

Age has often been reported as a factor affecting correct and consistent oral contraceptive use. Significantly, in the main comparative clinical trial conducted in North America, perfect use was consistent across age groups for the patch, while, as expected, rates of perfect use for oral contraceptives differed significantly by age (Archer et al 2002). Adolescents (the age group most vulnerable to forgetting to take oral contraceptives and/or unintentional mistakes and thus inadequate adherence) had the greatest increase in compliance with transdermal contraception over oral contraceptives $(87.7 \%$ vs 67.7\%) (Audet et al 2001). This significant advantage should be considered especially when counseling adolescents on contraceptive choices.

As a consequence of improved compliance, a base-case analysis showed that increased perfect use of the patch would result in a saving of US\$249 per woman over 2 years compared with oral contraceptives (Sonnenberg et al 2005).

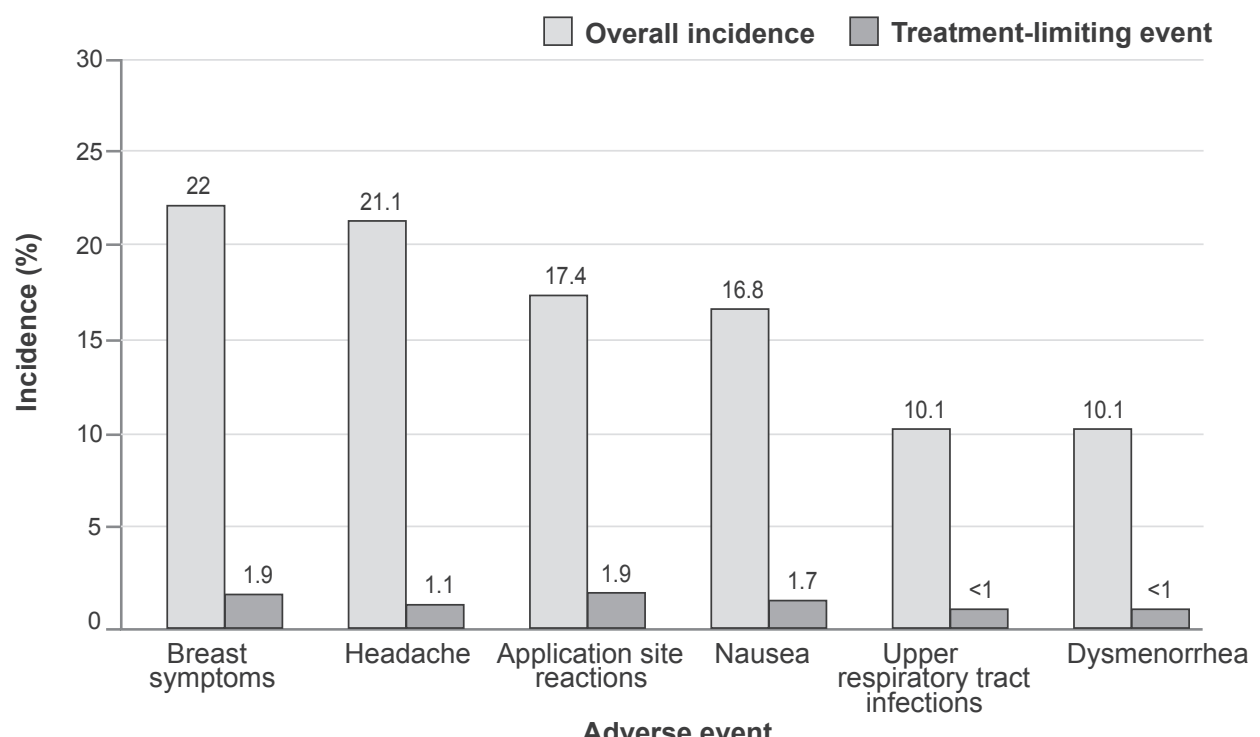

Adverse event

Figure 2 Most common adverse events in the three pooled contraceptive studies with the patch (From data of Sibai et al 2002). 
Transdermal contraception has further benefits, encouraging perfect use, in addition to its effectiveness in preventing unwanted pregnancies and its favorable safety profile. Most women consider the patch a convenient and simple method: in a recent study, more than $70 \%$ preferred or strongly preferred this contraceptive method compared with previous forms of contraception (Jakimiuk et al 2006b, Table 2). Convenience and simplicity of use were predominant factors in this high level of preference and contributed to the good acceptability of the patch.

\section{Patient adherence and acceptability}

When considering patient choices among contraceptive methods, the reasons for treatment compliance and adherence need to be carefully considered. As originally defined by Sackett in his 1976 landmark publication (Sackett et al 1976), the term compliance refers to the extent to which the behavior of the patient coincides with the doctor's order. The term compliance has long been criticized as denoting obedience by passive patients to doctors as authoritity figures, in the traditional hierarchical doctor/patient relationship. Therefore, a more consistent definition encompassing consensus was sought.

Adherence can also refer to a therapeutic plan, mutually agreed between patient and doctor, in which the patient expects to understand the information provided, and to co-operate by adding their personal perception and experience (Probstfield 1991). Because they actively "adhere" to therapeutic decisions, patients are involved in mutual decision

Table 2 Satisfaction, compliance and preference for the patch

573 women aged 18-46 years were enrolled to use the patch for six 4-week treatment cycles. In total, 467 women $(81.5 \%)$ completed the study. Most women $(410,71.5 \%)$ had been using a contraceptive method before the start of the study (Jakimiuk et al 2006b).

$\begin{array}{ll}\text { At baseline } & \\ \text { Satisfaction with their previous method of contraception } & 56.2 \% \\ \text { Oral contraceptive users reported missing doses (some, } & 38.7 \% \\ \text { most, or all of the time) } & \\ \text { After using transdermal contraception (6 cycles) } & \\ \text { Satisfaction } & 88 \% \\ \text { Satisfied or very satisfied with the patch } & 90 \% \\ \text { Find the patch convenient or very convenient } & \\ \text { Compliance } & 89.5 \% \\ \text { Cycles with perfect compliance } & \\ \text { Preference or strong preference for the patch } & 67.5 \% \\ \text { Shift from oral contraception } & 84.8 \% \\ \text { Shift from barrier contraception }\end{array}$

making with their doctor, reaching a "therapeutic alliance", a valuable predictor of favorable outcome.

However, adherence needs to be combined with persistence for the duration of treatment, to optimize efficacy and satisfaction with use. In this way, personal reward, can encourage repetition of the same behavior.

The major difference detected in the oral contraceptive failure rate with perfect use $(0.1 \%)$, and the failure rate in real life $(6.9 \%$ after 12 months) probably reflects at least some degree of dissatisfaction with available methods (Trussel and Vaughan 1999). Every physician prescribing a contraceptive should carefully evaluate patient satisfaction, and factors that could potentially enhance it. This satisfaction is closely related to the success of treatment, just as a favorable patient/ physician relationship influences treatment adherence. Oral contraceptive non-adherence can be explained in several ways, that is, early discontinuation (drop-outs), sporadic non-adherence due to forgetfulness and/or unintentional mistakes (inconsistent use), and systematic non-adherence over time (Table 3).

Early discontinuation is the most critical issue, as women who discontinue oral contraceptives often choose a less reliable contraceptive or no method at all, thus experiencing more unintended pregnancies. A significant predictor of early discontinuation is the occurrence of adverse events, with an increased risk of discontinuation as the number of adverse effects increases (Rosenberg et al 1995). Weight gain is the most commonly reported adverse event leading to drop out. It seems to be a subjective complaint, however, as no evidence of a causal association between hormonal contraception and weight gain was found by the Cochrane group in their recent systematic review (Gallo et al 2006).

Key predictors for inconsistent use are lack of an established routine for pill-taking and failure to understand instructions, thus emphasizing that quality of information provided by the physician and mutual decision making are influential in achieving long-term adherence.

As shown by measuring compliance using electronic devices, women tend to become less careful about their pill-taking behavior over time (Potter et al 1996). This change may reflect personalized schedules of use, learning to make up for occasional missed pills, or a kind of fatigue during continuous use. In addition, the same study showed that women tend to under-report their missed pills: the proportion of women missing at least three pills in a cycle according to the electronic data was triple that derived from the women's diaries (30\%-51\% vs 10\%-14\%). Missing pills were more likely to be clustered at the weekends and 
Table 3 Main determinants of compliance, adherence, and persistence

\begin{tabular}{|c|c|c|c|c|}
\hline \multirow[t]{2}{*}{ Compliance } & \multicolumn{3}{|l|}{ Adherence } & \multirow[t]{2}{*}{ Persistence } \\
\hline & $\begin{array}{l}\text { Early } \\
\text { discontinuation }\end{array}$ & Inconsistent usage & $\begin{array}{l}\text { Systematic "reasoned" } \\
\text { non-adherence }\end{array}$ & \\
\hline $\begin{array}{l}\text { Quality of doctor/patient } \\
\text { relationship (Probsfield 199I) }\end{array}$ & $\begin{array}{l}\text { Inconvenient usage } \\
\text { (WHO 2003) }\end{array}$ & $\begin{array}{l}\text { No established routine for } \\
\text { intake (Rosenberg et al 1998) }\end{array}$ & $\begin{array}{l}\text { Poor quality of doctor/ } \\
\text { patient relationship } \\
\text { (RamaRao et al 2003) }\end{array}$ & $\begin{array}{l}\text { Mutual decision making that } \\
\text { leads to rewards in the form } \\
\text { of personal need satisfaction } \\
\text { (Cramer et al 2008) }\end{array}$ \\
\hline $\begin{array}{l}\text { Active involvement of woman } \\
\text { (Probsfield 1991) }\end{array}$ & $\begin{array}{l}\text { Undesirable effects } \\
\text { (WHO 2003) }\end{array}$ & $\begin{array}{l}\text { Did not read or understand } \\
\text { package leaflet (Rosenberg } \\
\text { et al 1998) }\end{array}$ & $\begin{array}{l}\text { Couple conflicts } \\
\text { (Miller 1986) }\end{array}$ & \\
\hline \multirow[t]{4}{*}{$\begin{array}{l}\text { Active involvement of partner } \\
\text { (Probsfield 199I) }\end{array}$} & & $\begin{array}{l}\text { Inadequate instructions by } \\
\text { doctor (Rosenberg et al 1998) }\end{array}$ & & \\
\hline & & $\begin{array}{l}\text { Inconvenient usage (Rosenberg } \\
\text { et al 1998) }\end{array}$ & & \\
\hline & & $\begin{array}{l}\text { Undesirable effects (Rosenberg } \\
\text { et al 1998) }\end{array}$ & & \\
\hline & & $\begin{array}{l}\text { Negative partner attitude } \\
\text { towards hormonal contracep- } \\
\text { tion (Terefe and Larson 1993) }\end{array}$ & & \\
\hline
\end{tabular}

on consecutive days (Potter et al 1996), with a consequent increased risk of irregular bleeding and unintended pregnancies.

An analysis of women's self described reasons for missing pills showed that the three most reported reasons were being away from home, simply forgetting to take a pill, and not having the pill pack with them/being unable to obtain a new pack of pills in time for the beginning of the new cycle (Smith and Oakley 2005). Further predictors for inconsistent use are reported in Table 4.

To date, systematic "reasoned" non-adherence, whereby patients decide to change the dosage and/or dosing interval without informing the doctor, does not seem to have been adequately investigated. This kind of non-adherence can be avoided to some extent, by jointly establishing the ultimate objective, which differs according to the age of the woman. Evaluating a woman's particular needs or specific fears (including fear of forgetting to taking the pill, or fear of a negative effect on the body) and other such emotions including general anxiety which could foster inconsistent usage (Walsemann and Perez 2006) can help in doctor/ patient decision making. In a recent cross-sectional multicenter study, designed to assess the reasons for selecting the contraceptive pill, the skin patch, or the vaginal ring in 9700 women, the main reasons for choosing one type of hormonal treatment over another, consistent with the findings of previous studies, were convenience and frequency of use associated with lower probability of inadvertent omission (Lete et al 2007). In addition, including the husband in family planning programs has been shown to increase the use of modern contraception (Terefe and Larson 1993).

Adherence to treatment has been shown to be statistically superior for the transdermal patch compared with that observed with oral contraceptives (Figure 3), in all age groups (Archer et al 2004) and in all treatment cycles (Dittrich et al 2002). The same is true for user satisfaction: in a study presented at a recent conference (Jakimiuk et al 2006b), the mean satisfaction score was shown to increase

Table 4 Key predictors for inconsistent contraceptive use

Country of residence: significant differences among countries may reflect cultural differences, problem/free access to contraception, or different counseling attitudes

Low income: higher risk of contraceptive failure and lower likelihood of resuming contraceptive use, possibly due to education problems

Age: very young women are more likely to be inconsistent users than older women (Pons 2006)

Problems with access: difficulties in obtaining the contraceptive (Westhoff et al 2007)

Insufficient involvement of the partner (Terefe and Larson 1993)

Lack of contraceptive knowledge or negative experience with the contraceptive method (both associated with more requests for abortion) (Rasch et al 2007) 


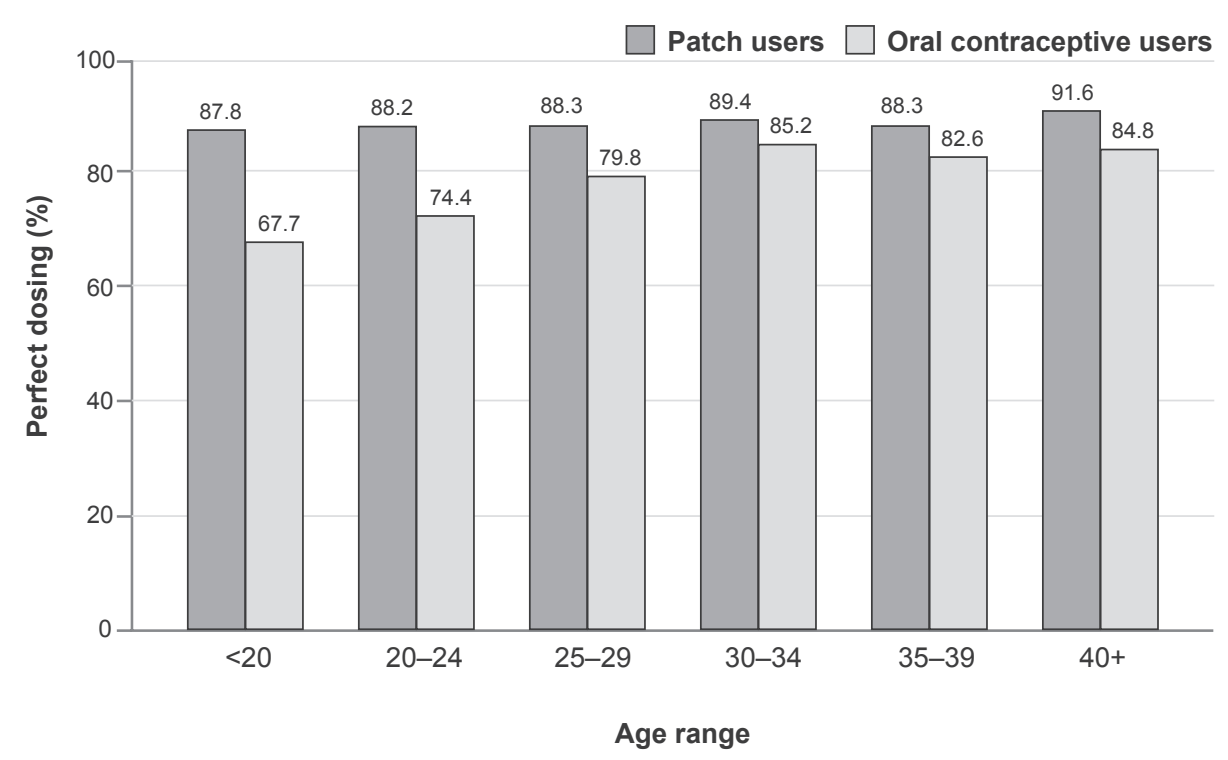

Figure 3 Percentage of cycles with perfect adherence, by age group. Comparison between patch and oral contraceptive users (From data of Archer et al 2004).

when women switched from previous contraceptive methods to the transdermal patch (Table 2).

Furthermore, in a recently published Cochrane review comparing contraceptive effectiveness and compliance in non-oral methods versus oral contraceptives, the authors concluded that although effectiveness was similar, the contraceptive patch group reported better compliance than the oral contraceptive group (odds ratio $=2.05$ and 2.76 in two trials). In one crossover ring trial greater non-compliance was reported by ring users (Lopez et al 2008).

\section{Benefits of hormonal contraception: tailoring treatment}

Today women are still largely unaware of the noncontraceptive health benefits associated with hormonal contraceptives (Table 5). Choosing a contraceptive method is a mutual decision that should take into account, besides the risks, the expected non-contraceptive benefits. A doctor should evaluate these with the woman in order to agree on a tailored program to achieve her adherence and persistence of use.

\section{Adolescents}

The most popular form of birth control among adolescents is oral contraceptives (Rubinstein et al 2004). However, adolescents tend to miss oral contraceptive pills, with a rate of failure close to $5 \%$ to $18 \%$, that is, approximately $55 \%$ higher than that found in adult users, leading to a greater risk of unintended pregnancies (Rubinstein et al 2004; Harel et al 2005). In addition, less than $60 \%$ of adolescents

Table 5 Well-established non-contraceptive benefits of hormonal methods

\begin{tabular}{|c|c|}
\hline Benefit & Mechanism \\
\hline Relief of dysmenorrhea & $\begin{array}{l}\text { Reduction of prostaglandin levels in menstrual fluid (French 2008); } \\
\text { reduction of heavy periods; symptomatic treatment of endometriosis }\end{array}$ \\
\hline Prevention of ovulation pain & Inhibition of ovulation (Jensen and Speroff 2000) \\
\hline Contribution to the resolution of iron-deficiency anemia & Reduction of blood loss and heavy periods (Petitti 2003) \\
\hline Treatment of polycystic ovary syndrome & $\begin{array}{l}\text { Inhibition of ovarian activity; reduction of androgen excess; regulation } \\
\text { of menstrual cycles (Yildiz 2008) }\end{array}$ \\
\hline Treatment of endometriosis & $\begin{array}{l}\text { Down regulation of the hypothalamus-pituitary-ovarian pathway (Rodgers } \\
\text { and Falcone 2008); reduced stimulation of endometrial ectopic tissue }\end{array}$ \\
\hline Reduction of the risk of endometrial cancer & $\begin{array}{l}\text { Progestin-mediated suppression of estrogen-induced proliferation } \\
\text { of endometrial cells (Petitti 2003; Hannaford et al 2007) }\end{array}$ \\
\hline Reduction of the risk of ovarian cancer & $\begin{array}{l}\text { Suppression of ovulation (suggested) (Petitti 2003; Hannaford et al 2007; } \\
\text { Collaborative Group on Epidemiological Studies of Ovarian Cancer 2008) }\end{array}$ \\
\hline
\end{tabular}


report perfect compliance with oral contraceptives, the rate of discontinuation within 1 year being approximately $64 \%$ (Rubinstein et al 2004).

A number of specific studies have examined adolescent use of the transdermal EE/NGMN contraceptive patch, confirming that it can provide a convenient form of reversible contraception (Logsdon et al 2004). Its ease of use and the fact that it does not require daily attention are well acknowledged by adolescents who have used it (Rubinstein et al 2004).

The finding that users of the transdermal EE/NGMN contraceptive patch generally experience minimal changes in body weight could be relevant to adolescent use, because weight gain is a significant predictor of early discontinuation of combined hormonal contraceptives in this age subgroup population (Harel et al 2005).

Improvement of facial acne, relief of dysmenorrheal symptoms, and reduction of heavy periods are further benefits. In a recent study of Thai adolescent women, participants reported a decrease in dysmenorrhea, shorter duration of bleeding, and an improvement of facial acne (Piyasirisilp and Taneepanichskul 2008). These data confirm the previously reported findings of Harel's study, that is, an improvement in the facial acne of one third of adolescents, and favorable results in a preliminary study of patch use among women suffering from papulo-pustular inflammatory acne. Clinical improvement started from the fourth month, with lesions almost disappearing in some patients (Caputo et al 2005). Furthermore, in women with acne vulgaris, an oral contraceptive containing norgestimate has been shown to be effective in normalizing skin-surface lipids in seborrheic areas, while skin hydration did not undergo any important changes (Sator et al 2003).

These therapeutic effects have been ascribed to the progestin component of the patch, which interacts selectively with the progesterone receptor and, therefore, does not stimulate androgen receptors (White et al 2005). Norgestimate, which is metabolized to norelgestromin, has negligible binding affinities for the androgen receptor and for the sex hormone-binding globulin (SHBG), reflecting the low androgenicity of this progestin, which is a desirable property particularly when signs of skin hyperandrogenism such as acne appear. In addition, the antiandrogenic activity of norgestimate and of norelgestromin has recently been demonstrated, using a human androgen-dependent stable-transfected cell line (Paris et al 2007). Finally, in skin tissue, norgestimate is a potent inhibitor of $5 \alpha$-reductase, the enzyme responsible for transforming testosterone in the more potent $5 \alpha$-dihydrotestosterone (Rabe et al 2000). Given these findings, the contraceptive EE/NGMN patch could be useful in women with disorders of androgen excess (White et al 2005).

\section{Adult women}

Some evidence indicates that the patch is particularly beneficial for emotional and physical well-being, and for premenstrual syndrome, which is more common in women over the age of 30 (Warner and Bancroft 1990).

Women who use the transdermal contraceptive patch have been reported to give higher ratings than oral contraceptive users when questioned on their emotional and physical wellbeing, and on improvements in premenstrual symptoms. In a randomized study comparing the patch with an oral contraceptive containing desogestrel and ethinyl estradiol, emotional and physical well-being were significantly higher with the patch than with the oral contraceptive, the difference being clustered in women aged 34 years and over. The same difference in improvement of premenstrual symptoms ( $p<0.01)$ favoring the contraceptive patch was found, once again especially in women aged 34 years and over (Urdl et al 2005).

These non-contraceptive beneficial effects may, at least in part, explain the high level of satisfaction reported by users of the transdermal patch and may contribute to their adherence to treatment.

\section{The perimenopause}

The perimenopause is a period lasting up to 5 to 6 years during which women experience menstrual cycle changes and may also experience typical menopausal signs and symptoms, such as bone mineral density loss, vasomotor instability, and joint pain. Some women erroneously believe that they no longer need contraception, although statistics show that up to $80 \%$ of women aged 40 to 44 years can conceive (Schmidt-Sarosi 1998). For these women, hormonal contraception, which offers protection against undesired pregnancy as well as correction of hormonal imbalance, is more suitable than hormone replacement therapy, which offers only the latter (Kaunitz 2001).

In hormonal combinations, contraceptives containing norgestimate have demonstrated prominent changes in bone resorption and formation markers in patients with hypothalamic amenorrhea, a young population experiencing significant bone loss (Grinspoon et al 2003). These findings suggest that suitable hormonal combinations can decrease the rate of bone turnover and attenuate bone loss in at risk 
populations, such as perimenopausal women (appropriate calcium and vitamin D daily intake must be checked and integrated if necessary).

In conclusion, in a mutual decision making process with their physician, healthy perimenopausal women can be assured that the transdermal patch is a useful and reliable contraceptive method, and an alternative to oral formulations, which can improve perimenopausal symptoms, reduce some long-term health risks, and enhance quality of life (Kaunitz 2001).

\section{Satisfaction with the transdermal patch}

Because human behavior tends to be repeated when rewarded, satisfaction with a contraceptive method is essential for longterm adherence, and depends mainly on selecting the optimal contraceptive for the couple (Table 3).

A large European study compared patient attitudes (satisfaction and preference) toward the transdermal contraceptive patch and toward previous contraceptive methods. Of all the women surveyed, $88 \%$ said that they were satisfied or very satisfied with the patch and $70.1 \%$ preferred the patch to their previous method of contraception, which in $72.4 \%$ had been an oral contraceptive. The main reasons for this preference were: convenience (40.9\%), ease of use/simplicity (31.5\%), and fewer side effects (19.3\%) (Jakimiuk et al 2006b).

In another similar study $74.9 \%$ of women preferred the patch, mainly because of its convenience (50.2\%) and simplicity (32.5\%); 91\% were satisfied or very satisfied with the patch (Weisberg et al 2005).

Another clinical study showed that patch users were significantly more satisfied with their contraceptive than users of oral contraceptives ( $p=0.001)$, and that satisfaction was associated with duration of use and mental well-being (Wan et al 2007).

Patch users sometimes refer to inconveniences, which can depend either on the transdermal route of administration or on the hormonal mode of action. These include application site reactions or pruritus, mainly in subjects with irritated or sensitive skin (but $<2 \%$ of participants discontinued treatment for this reason), incomplete adhesive reliability (although only a minimal proportion of patches requires replacement), patch visibility (which is a problem for only a limited subset of subjects; applying the patch to the buttock or to lower abdomen guarantees discretion), appearance of a dark ring around the patch (probably due to adhesive components; washing the area normally where the patch is attached could resolve this inconvenience), unpredictable vaginal bleeding (an adverse event, common even with oral contraceptives, which generally decreased over time) (Audet et al 2001; Sibai et al 2002). Therefore, a further optimization of structural support and hormones of the patch could help improve esthetics and cutaneous tolerability, and reduce breakthrough bleeding or spotting.

\section{Conclusions}

The transdermal EE/NGMN contraceptive patch is an excellent choice for women of any age who desire convenient, easy-to-use, reversible, hormonal contraception. The contraceptive efficacy of the patch is comparable with that of oral contraceptives while adherence and persistence of use are consistently better for the patch in all age groups. The patch enables a contraceptive to be tailored to suit the needs of women of all ages and characteristics. Combined with a valuable doctor-patient relationship which permits the development of a therapeutic alliance, the patch has received higher satisfaction ratings in addition to ensuring effectiveness and safety.

\section{Disclosures}

Dr Graziottin has served on the Speakers' Bureau for Bayer-Schering Healthcare, Boeringher-Ingelheim, Janssen-Cilag, and Procter and Gamble, and as a consultant for Theramex.

\section{References}

Abrams LS, Skee DM, Natarajan J, et al. 2001. Pharmacokinetics of norelgestromin and ethinyl estradiol delivered by a contraceptive patch (Ortho Evra ${ }^{\mathrm{TM}} / \mathrm{Evra}^{\mathrm{TM}}$ ) under conditions of heat, humidity and exercise. J Clin Pharmacol, 41:1301-9.

Archer DF, Bigrigg A, Smallwood GH, et al. 2002. Assessment of compliance with a weekly contraceptive patch (Ortho Evra ${ }^{\mathrm{TM}} /$ Evra $^{\mathrm{TM}}$ ) among North American women. Fertil Steril, 77(2, Suppl 2): S27-S30.

Archer DF, Cullins V, Creasy GW, et al. 2004. The impact of improved compliance with a weekly contraceptive transdermal system (Ortho Evra $\left.^{\circledR}\right)$ on contraceptive efficacy. Contraception, 69:189-95.

Audet MC, Moreau M, Koltun WD, et al. 2001. Evaluation of contraceptive efficacy and cycle control of a transdermal contraceptive patch vs an oral contraceptive. A randomized controlled trial. JAMA, 285:2347-54.

Burkman RT. 2007. Transdermal hormonal contraception: benefits and risks. Am J Obstet Gynecol, 197:134e1-6.

Caputo R, Barbareschi M, Lunardon L. 2005. A patch-released norelgestromin and ethinyl estradiol association in the treatment of papulo-pustular inflammatory acne. G Ital Dermatol Venereol, 140:727-32.

Cole JA, Norman H, Doherty M, et al. 2007. Venous thromboembolism, myocardial infarction, and stroke among transdermal contraceptive system users. Obstet Gynecol, 109:339-46.

Collaborative Group on Epidemiological Studies of Ovarian Cancer. 2008. Ovarian cancer and oral contraceptives: collaborative reanalysis of data from 45 epidemiological studies including 23,257 women with ovarian cancer and 87,303 controls. Lancet, 371:303-14.

Cramer JA, Roy A, Burrell A, et al. 2008. Medication compliance and persistence: terminology and definitions. Value Health, 11:44-7. 
Creasy GW, Abrams LS, Fisher AC. 2001. Transdermal contraception. Semin Reprod Med, 19:373-80.

Dittrich R, Parker L, Rosen JB, et al. 2002. Transdermal contraception: evaluation of three transdermal norelgestromin/ethinyl estradiol doses in a ranmdomised, multicenter, dose-response study. Am J Obstet Gynecol, 186:15-20.

D'Souza RE, Guillebaud J. 2002. Risks and benefits of oral contraceptive pills. Best Pract Res Clin Obstet Gynecol, 16:133-54.

French L. 2008. Dysmenorrhea in adolescents: diagnosis and treatment. Paediatr Drugs, 10:1-7.

Gallo MF, Lopez LM, Grimes DA, et al. 2006. Combination contraceptives: effects on weight. Cochrane Database of Systematic Reviews, Issue 1. Art. No: CD003987. DOI: 10.1002/14651858.CD003987.pub2.

Grinspoon SK, Friedman AJ, Miller KK, et al. 2003. Effects of a triphasic combination oral contraceptive containing norgestimate/ethinyl estradiol on biochemical markers of bone metabolism in young women with osteopenia secondary to hypothalamic amenorrhea. J Clin Endocrinol Metab, 88:3651-6.

Hannaford PC, Selvaraj S, Elliott AM, et al. 2007. Cancer risk among users of oral contraceptives: cohort data from the Royal College of General Practitioner's oral contraception study. BMJ, 335:651-9.

Harel Z, Riggs S, Vaz R, et al. 2005. Adolescents' experience with the combined estrogen and progestin transdermal contraceptive method Ortho Evra. J Pediatr Adolesc Gynecol, 18:85-90.

Hedon B, Helmerhorst FM, Cronje HS, et al. 2000. Comparison of efficacy, cycle control, compliance, and safety in users of a contraceptive patch vs an oral contraceptive. Int J Gynecol Obstet, 70(Suppl 1):78.

Jakimiuk A, Madelenet P, Chernev T, et al. 2006a. Efficacy and tolerability of transdermal hormonal contraception over 6 months. Eur J Contracept Reprod Health Care, 11(S1):P024,66-7.

Jakimiuk A, Madelenet P, Chernev T, et al. 2006b. Transdermal contraception is associated with high levels of patient satisfaction and compliance. Eur J Contracept Reprod Health Care, 11(S1):P028,68-9.

Jensen JT, Speroff L. 2000. Health benefits of oral contraceptives. Obstet Gynecol Clin North Am, 27:705-21.

Jick SS, Jick H. 2006. Cerebral venous sinus thrombosis in users of four hormonal contraceptives: levonorgestrel-containing oral contraceptives, norgestimate-containing oral contraceptives, desogestrel-containing oral contraceptives and the contraceptive patch. Contraception, 74:290-2.

Jick SS, Kaye JA, Russmann S, et al. 2006. Risk of nonfatal venous thromboembolism in women using a contraceptive transdermal patch and oral contraceptives containing norgestimate and $35 \mathrm{mcg}$ of ethinyl estradiol. Contraception, 73:223-8.

Jick SS, Jick H. 2007. The contraceptive patch in relation to ischemic stroke and acute myocardial infarction. Pharmacotherapy, 27:218-20.

Jick S, Kaye JA, Li L, et al. 2007. Further results on the risk of nonfatal venous thromboembolism in users of the contraceptive transdermal patch compared to users of oral contraceptives containing norgestimate and $35 \mathrm{mcg}$ of ethinyl estradiol. Contraception, 76:4-7.

Johnson JV, Lowell J, Badger GJ. 2008. Effects of oral and transdermal hormonal contraception on vascular risk markers. Obstet Gynecol, 111:270-283.

Kaunitz AM. 2001. Oral contraceptive use in perimenopause. Am J Obstet Gynecol, 185:S32-7.

Kluft C, Meijer P, LaGuardia KD, et al. 2008. Comparison of a transdermal contraceptive patch vs oral contraceptives on hemostasis variables. Contraception, 77:77-83.

Lete I, Doval JL, Pérez-Campos E, et al. 2007. Factors affecting women's selection of a combined hormonal contraceptive method: the TEAM-06 Spanish cross-sectional study. Contraception, 76:77-83.

Lippman JS, Shangold GA. 1997. A review of post-marketing safety and surveillance data for oral contraceptives containing norgestimate and ethinyl estradiol. Int $J$ Fertil, 42:230-9.

Logsdon S, Richards J, Omar HA. 2004. Long-term evaluation of the use of the transdermal contraceptive patch in adolescents. The Scientific World, 4:512-6.
Lopez LM, Grimes DA, Gallo MF, et al. 2008. Skin patch and vaginal ring versus combined oral contraceptives for contraception. Cochrane Database of Systematic Reviews, Issue 1. Art. No: CD003552. DOI: 10.1002/14651858.CD003552.pub2.

Miller WB. 1986. Why some women fail to use their contraceptive method: a psychological investigation. Fam Plann Perspect, 18:27-32.

O'Connell K, Burkman RT. 2007. The transdermal contraceptive patch: an updated review of the literature. Clin Obstet Gynecol, 50:918-26.

Paris F, Rabeolina F, Balaguer P, et al. 2007. Antiandrogenic activity of norgestimate in a human androgen-dependent stable transfected cell line. Gynecol Endocrinol, 23:193-7.

Petitti DB. 2003. Combination estrogen-progestin oral contraceptives. N Engl J Med, 349:443-50.

Pierson RA, Archer DF, Moreau M, et al. 2003. Ortho Evra ${ }^{\mathrm{TM}} / \mathrm{Evra}^{\mathrm{TM}}$ versus oral contraceptives: follicular development and ovulation in normal cycles and after an intentional dosing error. Fertil Steril, 80:34-42.

Piyasirisilp R, Taneepanichskul S. 2008. A clinical study of transdermal contraceptive patch in Thai adolescence women. J Med Assoc Thai, 91:137-41.

Pons JE. Hormonal contraception compliance in teenagers. 2006. Pediatr Endocrinol Rev, 3(Suppl 1):164-6.

Potter L, Oakley D, De Leon-Wong E, et al. 1996. Measuring compliance among oral contraceptive users. Fam Plann Perspect, 28:154-8.

Probstfield JL. The clinical trial pre-randomization compliance (adherence) screen. 1991. In: Cramer JA, Spilker B (eds). Patients compliance in medical practice and clinical trials. New York: Raven Press. p. 323-34.

Prausnitz MR, Mitragotri S, Langer R. 2004. Current status and future potential of transdermal drug delivery. Nature Rev Drug Discov, $3: 115-24$

Rabe T, Kowald A, Ortmann J, et al. 2000. Inhibition of skin 5 alphareductase by oral contraceptive progestins in vitro. Gynecol Endocrinol, 14:223-30.

RamaRao S, Lacuesta M, Costello M, et al. 2003. The link between quality of care and contraceptive use. Int Fam Plan Perspect, 29:76-83.

Rasch V, Knudsen LB, Gammeltoft T, et al. 2007. Contraceptive attitudes and contraceptive failure among women requesting induced abortion in Denmark. Hum Reprod, 22:1320-6.

Rodgers AK, Falcone T. 2008. Treatment strategies for endometriosis. Expert Opin Pharmacother, 9:243-55.

Rosenberg MJ, Waugh MS, Meehan TE. 1995. Use and misuse of oral contraceptives: risk indicators for poor pill taking and discontinuation. Contraception, 51:283-8.

Rosenberg MJ, Waugh MS, Burnhill MS. 1998. Compliance, counseling and satisfaction with oral contraceptives: a prospective evaluation. Fam Plann Perspect, 30(2):89-92.

Rubinstein ML, Halpern-Felsher BL, Irwin CE. 2004. An evaluation of the use of the transdermal contraceptive patch in adolescents. J Adolesc Health, 34:395-401.

Sackett DL. Introduction. 1976. In: Sackett DL, Haynes RB (eds). Compliance with therapeutic regimens. Baltimore: Johns Hopkins University Press.

Sator PG, Schmidt JB, Honigsmann H. 2003. Clinical evidence of the endocrinological influence of a triphasic oral contraceptive containing norgestimate and ethinyl estradiol in treating women with acne vulgaris. Dermatology, 206:241-8.

Schmidt-Sarosi C. 1998. Infertility in the older woman. Clin Obstet Gynecol, 41:940-50.

Sibai BM, Odlind V, Meador ML, et al. 2002. A comparative and pooled analysis of the safety and tolerability of the contraceptive patch (Ortho Evra $^{\mathrm{TM}} /$ Evra $^{\mathrm{TM}}$ ). Fertil Steril, 77(Suppl 2):S19-S26.

Smallwood GH, Meador ML, Lenihan JP, et al. 2001. Efficacy and safety of a transdermal contraceptive system. Obstet Gynecol, 98:799-805.

Smith JD, Oakley D. 2005. Why do women miss oral contraceptive pills? An analysis of women's self-described reasons for missed pills. J Midwifery Womens Health, 50:380-5. 
Sonnenberg FA, Burkman RT, Speroff L, et al. 2005. Cost-effectiveness and contraceptive effectiveness of the transdermal contraceptive patch. Am J Obstet Gynecol, 192:1-9.

Terefe A, Larson CP. 1993. Modern contraception use in Ethiopia: does involving husbands make a difference? Am J Public Health, 83:1567-71.

Trussell J, Vaughan B. 1999. Contraceptive failure, method-related discontinuation and resumption of use: results from the 1995 National Survey of Family Growth. Fam Plann Perspect, 31:64-72.

Urdl W, Apter D, Alperstein A, et al. 2005. Contraceptive efficacy, compliance and beyond: factors related to satisfaction with once-weekly transdermal compared with oral contraception. Eur J Obstet Gynecol Reprod Biol, 121:202-10.

Walsemann KM, Perez AD. 2006. Anxiety's relationship to inconsistent use of oral contraceptives. Health Educ Behav, 33:197-214.

Wan GJ, Barnowski CE, Ambegaonkar BM, et al. 2007. Treatment satisfaction with a transdermal contraceptive patch or oral contraceptives. Contraception, 75:281-4.

Warner P, Bancroft J. 1990. Factors related to self-reporting of the premenstrual syndrome. Br J Psychiatry, 157:249-60.
Weisberg F, Bouchard C, Moreau M, et al. 2005. Preference for and satisfaction of Canadian women with the transdermal contraceptive patch versus previous contraceptive method: an open-label, multicenter study. J Obstet Gynaecol Can, 27:350-9.

Westhoff CL, Heartwell S, Edwards S, et al. 2007. Oral contraceptive discontinuation: do side effects matter? Am J Obstet Gynecol, 196:412e1-7.

White T, Jain JK, Stanczyk FZ. 2005. Effect of oral versus transdermal steroidal contraceptives on androgenic markers. Am J Obstet Gynecol, 192:2005-59.

WHO. Adherence to long-term therapies. 2003. Evidence for action. Geneva, Switzerland.

Yildiz BO. 2008. Oral contraceptives in polycystic ovary syndrome: risk-benefit assessment. Semin Reprod Med, 26:111-20.

Zacur HA, Hedon B, Mansour D, et al. 2002. Integrated summary of Ortho Evra $^{\mathrm{TM}} / \mathrm{Evra}^{\mathrm{TM}}$ contraceptive patch adhesion in varied climates and conditions. Fertil Steril, 77:S32-5.

Zieman M, Guillebaud J, Weisberg E, et al. 2002. Contraceptive efficacy and cycle control with the Ortho Evra ${ }^{\mathrm{TM}} / \mathrm{Evra}^{\mathrm{TM}}$ transdermal system: the analysis of pooled data. Fertil Steril, 77:S13-8. 
